\title{
N-Acetyl cysteine use in trichotillomania: dramatic improvement in two children
}

\begin{abstract}
$\mathrm{N}$-Acetyl cysteine (NAC) has been increasingly used for several psychiatric conditions such as autism spectrum disorders, obsessive compulsive disorder, hoarding disorder etc. Here we report two cases with diagnosis of trichotillomania who had been treated with NAC successfully.
\end{abstract}

Volume 9 Issue 2 - 2019

\begin{abstract}
Nevzat Yılmaz, Sevcan Karakoç Demirkaya, Hatice Aksu, Hacer Demir
\end{abstract}

Child and Adolescent Psychiatry, Adnan Menderes University School of Medicine, Turkey

Correspondence: Sevcan Karakoç Demirkaya, Child and Adolescent Psychiatry, Adnan Menderes University School of Medicine,Aydin,Turkey, Email drsevcankarakoc@yahoo.com

Received: May 25, 2017 | Published: April 19, 2019

\section{Introduction}

Trichotillomania is in the class of ' Obsessive-Compulsive Disorder (OCD) and Associated Disorders" in DSM-5 ${ }^{1}$ and characterized by repetetive hair pulling resulting in hair loss. $\mathrm{N}$-acetylcysteine (NAC) is a precursor to the aminoacid cysteine, a modulator of the glutamatergic system and has role in oxidative stress. ${ }^{2}$ It has been shown that NAC is effective in various psychiatric problems especially in OCD and related disorders. ${ }^{2-5}$ Here we report two cases with trichotillomania who were treated with NAC successfully.

\section{Case reports}

Our first case was a 11-year-old girl with symptoms of eyebrow and eyelash picking for six months. After 3months of treatment wth risperidone (2,5mg/day) and fluoxetine $(20 \mathrm{mg} /$ day $)$ due to side-effects and low compliance NAC $600 \mathrm{mg} /$ day monotherapy was started. The maintenance NAC dose was $1200 \mathrm{mg}$ /day. Her baseline and 2-months duration endpoint Clinical Global impression scale disease severity (CGI-S) score was 5 (markedly ill) and 1 (Normal, not at all ill) respectively.

Our second case was a 16-year-old male patient with complaints of hair pulling for 2 months. Due to experience adverse effects with fluoxetine $20 \mathrm{mg}$ /day NAC (600mg/day) was started as a monotherapy. The maintenance NAC dose was $1200 \mathrm{mg}$ /day. His baseline CGI-S score was 5. After 2 months of NAC treatment, final score was 2 (borderline ill). Both of the cases responded well without any adverse effect.

\section{Conclusion}

Although a recent study in pediatric trichotillomania, NAC showed no superiority over placebo in a randomized controlled addon- trial; ${ }^{2}$ symptom reductions are reported with NAC use pediatric case reports. ${ }^{6,7}$ Our cases tolerated and responded well to NAC monotherapy. This report shows that NAC may be a safe choice in treatment of pediatric trichotillomania. Pharmacologic modulation of the glutamate system may prove to be useful in the control of other obsessive compulsive and related behaviors.

\section{Acknowledgments}

None.

\section{Conflicts of interest}

Author declare thier is no conflicts of interestowards the artilce.

\section{References}

1. Diagnostic and Statistical Manual of Mental Disorders. 5th edn, Washington: American Psychiatric Association; 2013.

2. Berk M, Malhi GS, Gray LJ, et al. The promise of N-acetylcysteine in neuropsychiatry. Trends Pharmacol Sci. 2013;34(3):167-177.

3. Afshar H, Roohafza H, Mohammad-Beigi H, et al. N-acetylcysteine addon treatment in refractory obsessive-compulsive disorder: a randomized, double-blind, placebo controlled trial. $J$ Clin Psychopharmacol. 2012;32(6):797-803

4. Ghanizadeh A, Derakhshan N, Berk M. N-acetylcysteine versus placebo for treating nail biting, a double blind randomized placebo controlled clinical trial. Antiinflamm Antiallergy Agents Med Chem. 2013;12(3):223-228.

5. Grant JE, Odlaug BL, KimSW. N-acetylcysteine, a glutamatemodulator, in the treatment of trichotillomania: a double-blind, placebo-controlled study. Arch Gen Psychiatry. 2009;66(7):756-763.

6. Bloch MH, Panza KE, Grant JE, et al. N-Acetylcysteine in the treatment of pediatric trichotillomania: a randomized, double-blind, placebo-controlled add-on trial. J Am Acad Child Adolesc Psychiatry. 2013;52(3):231-240.

7. Rodrigues-Barata AR, Tosti A, Rodríguez-Pichardo A, et al. $\mathrm{N}$-acetylcysteine in the Treatment of Trichotillomania. Int J Trichology. 2012;4(3):176-178. 